\title{
QUEEN'S
UNIVERSITY
BELFAST
}

\section{Putative periodontal pathogens in the subgingival plaque of Sudanese subjects with aggressive periodontitis}

Hashim, N. T., Linden, G. J., Winning, L., Ibrahim, M. E., Gismalla, B. G., Lundy, F. T., \& El Karim, I. A. (2017). Putative periodontal pathogens in the subgingival plaque of Sudanese subjects with aggressive periodontitis. Archives of Oral Biology, 81, 97-102. https://doi.org/10.1016/j.archoralbio.2017.04.027

Published in:

Archives of Oral Biology

Document Version:

Peer reviewed version

Queen's University Belfast - Research Portal:

Link to publication record in Queen's University Belfast Research Portal

\section{Publisher rights}

Copyright 2017 Elsevier.

This manuscript is distributed under a Creative Commons Attribution-NonCommercial-NoDerivs License

(https://creativecommons.org/licenses/by-nc-nd/4.0/), which permits distribution and reproduction for non-commercial purposes, provided the author and source are cited

\section{General rights}

Copyright for the publications made accessible via the Queen's University Belfast Research Portal is retained by the author(s) and / or other copyright owners and it is a condition of accessing these publications that users recognise and abide by the legal requirements associated with these rights.

Take down policy

The Research Portal is Queen's institutional repository that provides access to Queen's research output. Every effort has been made to ensure that content in the Research Portal does not infringe any person's rights, or applicable UK laws. If you discover content in the Research Portal that you believe breaches copyright or violates any law, please contact openaccess@qub.ac.uk. 
Putative periodontal pathogens in the subgingival plaque of Sudanese subjects with aggressive periodontitis

Running Title: Periodontal pathogens and AgP in Sudan

Authors: N. T. HASHIM ${ }^{1}$, G. J. LINDEN ${ }^{2}$, L. WINNING ${ }^{3}$, M. E. IBRAHIM ${ }^{4}$, B. G. GISMALLA $^{1}$, F.T. LUNDY ${ }^{3}$, I. A. El KARIM ${ }^{3}$

${ }^{1}$ Faculty of Dentistry, University of Khartoum, Khartoum, Sudan

${ }^{2}$ Centre for Public Health, Queen's University Belfast, Belfast, United Kingdom.

${ }^{3}$ Centre for Experimental Medicine, Queen's University Belfast, Belfast, United Kingdom

${ }^{4}$ Institute of Endemic diseases, University of Khartoum, Khartoum, Sudan

\section{Corresponding author: Dr. Ikhlas El Karim}

Centre for Experimental Medicine, School of Medicine, Dentistry and Biomedical Sciences, Queen's University Belfast, The Wellcome-Wolfson Building, 97 Lisburn Road, Belfast, BT9 7BL, Northern Ireland, United Kingdom

Tel: +442890976026

Email: i.elkarim@qub.ac.uk

Key words: Aggressive periodontitis, periodontal pathogens 
Highlights

- The article describe the prevalence of putative periodontal pathogens in high risk population for aggressive periodontitis ( $\mathrm{AgP})$ using qPCR

- The association of the bacteria with the cases of AgP depend on the detection threshold level

- Pathogen of the red complex particularly T. forsythia and T. denticola had a high prevalence ( $>70 \%$ ) in AgP cases at all detection levels, while $P$. gingivalis was more prevalent in case at the lowest detection threshold

A. actinomycetemcomitans was identified less frequently than the other bacterial species with no difference in its prevalence between cases and controls 


\section{Abstract}

Background and objectives: There has been limited study of the bacterial species associated with aggressive periodontitis (AgP) in high-risk populations in Africa. The aim of this study was to investigate and quantify the presence of four putative periodontal pathogens in the subgingival plaque of Sudanese subjects with AgP. A secondary aim was to investigate the effect of varying the detection threshold on the reported prevalence of the bacterial species investigated. Materials and methods: Subgingival plaque samples were collected from AgP cases $(n=73)$ and healthy controls $(n=71)$. Bacterial DNA was extracted and analyzed by quantitative polymerase chain reaction for the detection and quantification of four putative periodontal pathogens: Porphyromonas gingivalis, Aggregatibacter actinomycetemcomitans, Treponema denticola and Tannerella forsythia. Results: At the lowest detection threshold (> 101 cells $), P$. gingivalis $(\mathrm{p}<0.0001)$ was more prevalent in $\mathrm{AgP}$ cases than controls. T. forsythia and T. denticola had a high prevalence $(>70 \%)$ in $\mathrm{AgP}$ cases at all detection levels. While T. forsythia was significantly more frequently identified in AgP than in controls at all detection thresholds, this was only the case for T. denticola at the intermediate threshold ( $>102$ cells). A. actinomycetemcomitans was identified less frequently than the other bacterial species with no difference in its prevalence between $\mathrm{AgP}$ cases and controls. Conclusion: The prevalence of the putative periodontal pathogens investigated varied considerably in Sudanese subjects with AgP and in periodontally healthy controls depending on the detection thresholds applied. T. forsythia was identified as having the strongest association with AgP. 


\section{Introduction}

The term aggressive periodontitis ( $\mathrm{AgP})$ was introduced by the International Workshop for the Classification of Periodontal Diseases and Conditions (Armitage, 1999). It is a relatively uncommon condition where there is rapid loss of periodontal tissue including alveolar bone, and can present in localised or generalised forms. The disease tends to occur in adolescents or young adults who do not display the classically defined periodontal risk factors, and there is usually a familial tendency suggesting a certain genetic susceptibility to the disease. The disease progression observed in $\mathrm{AgP}$ is considered sufficiently different from the generally slow linear destruction observed in chronic periodontitis, as to be considered a separate disease. The prevalence of $\mathrm{AgP}$ varies between populations, and differences in ethnicities seem to be a key factor. It is most prevalent in Africa and in populations of African descent (1-5\%) and least prevalent (0.1\%) in Caucasians in Europe and North America (Susin et al., 2014).

A recent review has highlighted the complex microbial aetiology of AgP (Kononen \& Muller, 2014). Of the potential putative pathogens involved, much research has focused on Aggregatibacter actinomycetemcomitans as the major pathogen associated with localised AgP (LAgP). It has been suggested that $A$. actinomycetemcomitans can be transmitted from family members at an early age in life (Asikainen et al., 1996, Dogan et al., 2008). However, the great genetic diversity of A. actinomycetemcomitans has resulted in both harmless and highly virulent variants of the species. The JP2 clone of A. actinomycetemcomitans, a genetic variant with increased leukotoxic activity, is considered as a risk factor for initiation of attachment loss (Höglund Åberg et al., 2014). Since A. actinomycetemcomitans can live in both the presence and absence of oxygen, it is associated with early colonization of the ecological niche.

A prospective study of adolescent schoolchildren in Morocco established that the JP2 clone of A. actinomycetemcomitans, caused LAgP (Haubek et al., 2008). The JP2 clone is prevalent in 
populations from North and West Africa, however it is responsible for only a small fraction of all cases of LAgP (Haubek et al., 2008, Höglund Åberg et al., 2014) Other prospective investigations (Fine et al., 2007; Fine et al., 2013) have supported a role for $A$. actinomycetemcomitans in the initiation and progression of AgP, however, not all studies have identified this species, even in very young individuals who present with early signs of periodontal destruction (Albandar et al., 1997). Recent data have shown $A$. actinomycetemcomitans to be less prevalent in deep pockets and at sites with attachment loss of $>3 \mathrm{~mm}$ (Dahlén et al., 2014). As the periodontal pocket progressively deepens the ecology shifts towards an anaerobic highly proteolytic condition, with $A$. actinomycetemcomitans being replaced by the obligate anaerobic periodontal pathogens of the red complex. In support of this studies of subjects with generalised $\mathrm{AgP}$ (GAgP) tend to show more heterogeneity of microorganisms, with red and orange complex organisms such as Porphyromonas gingivalis and Tannerella forsythia being frequently detected in plaque samples (Lopez et al., 1996; Takeuchi et al., 2003; Kamma et al., 2004; Riep et al., 2009).

Studies focused on high-risk populations are important to investigate the determinants of AgP and provide information which might result in effective health-promotion measures (Susin et al., 2014). An epidemiological study of 13-19 year-old students from high schools in Khartoum, Sudan identified AgP in 3.4\% (Elamin et al., 2010). A follow-up study identified $A$. actinomycetemcomitans in the majority (71\%) of those with AgP but the JP2 clone was not detected in any of the subjects (Elamin et al., 2011). However, more recently $A$. actinomycetemcomitans was found in only $29 \%$ of AgP patients seeking treatment at a specialist unit in Khartoum (Elabdeen et al., 2015) and the JP2 clone was identified in only one patient. Differences found within and between populations may in part reflect differences in the methods used to detect various bacterial species. It is hypothesized that using methods with low 
detection limits, such as polymerase chain reaction (PCR), will increase the probability of identifying specific bacterial species. The present study aimed to investigate the presence of four putative periodontal pathogens in the subgingival plaque of a well characterized cohort with AgP in Sudan. A secondary aim was to investigate the effect of varying the threshold detection limit on the reported prevalence of the bacterial species investigated.

\section{Materials and Methods}

\section{Study population}

The cases were 73 subjects (18 males, 55 females) with AgP recruited from patients seeking treatment at the Department of Periodontology, Khartoum Dental Teaching Hospital, Faculty of Dentistry, University of Khartoum. The controls were 71 periodontally healthy subjects (23 males, 48 females) recruited from patients attending non-periodontal clinics in the same hospital, matched for age and ethnicity (based on tribal origin) to those recruited with AgP. All subjects were examined under ideal conditions in a dental clinic by a single examiner, who was an experienced specialist periodontist (N.T.H.). Full-mouth measures of probing pocket depths (PPD) and clinical attachment levels (CAL) were obtained at 6 points per tooth. The controls in some cases had evidence of gingival inflammation but had no evidence of periodontitis with no PPD or CAL $>3 \mathrm{~mm}$. Demographic information collected for those investigated included age, gender, tribal affiliation and information regarding smoking. All subjects were informed about the nature of the study and provided written consent. The study protocol was approved by the Faculty of Dentistry, University of Khartoum Health Research Ethics Committee (HREC assigned number 1/2008).

\section{Inclusion Criteria}


Patients with $\mathrm{AgP}$ were diagnosed and selected based on a number of criteria including age, severity of interproximal attachment loss assessed clinically and bone loss as observed on radiographic examination (Hodge et al., 2000) (Supp table 1). Radiographic examination, which included an orthopantomogram and intraoral views, was also performed for each subject with a clinical diagnosis of $\mathrm{AgP}$ to confirm the diagnosis. Subjects with AgP were classified as localized or generalized by applying the criteria of the 1999 World Workshop for the Classification of Periodontal Diseases and Conditions (Armitage, 2004) according to the number and type of teeth affected. The disease was considered localized (LAgP) when there was attachment loss affecting less than 8 teeth including incisors and first molars, whereas generalized (GAgP) was defined when there was generalized attachment loss on 8 or more teeth, at least 3 of which were not first molars or incisors.

\section{Exclusion criteria}

Subjects were excluded if they were not Sudanese nationals, had diseases or conditions that could pose health risks to the participants or examiners, had medical conditions identified by self-report, such as diabetes or neutropenias that could influence their periodontal condition, had received a course of antibiotics within the previous month, or had received periodontal treatment prior to the commencement of the study and collection of plaque samples.

\section{Microbiological sampling}

During the initial clinical assessment PPD were obtained at 6 points per tooth and in cases only sites with $\mathrm{PPD} \geq 5 \mathrm{~mm}$ were considered for microbiological sampling at a subsequent visit. Subgingival plaque was collected from the most accessible mesial and distal sites of molars and incisors in both AgP cases and controls. Sample sites were isolated with cotton rolls and air dried. Supragingival plaque was carefully removed with a sterile curette and paper points 
( $\neq 40$ Dentsply, Ballaigues, Switzerland) were then inserted to the depth of the pockets and held in place for 10 seconds. 5 samples were collected from each patient and the paper points were immediately placed into sterile Eppendorf tubes kept on ice and transported to the laboratory. Samples were stored at $-80^{\circ} \mathrm{C}$ until processed for DNA extraction which was performed within 12 months of sampling.

\section{Plaque DNA extraction and quantitative real time PCR ( $q P C R)$}

The total plaque genomic DNA of the bacterial samples was isolated by means of a DNA purification kit (DNeasy, Qiagan, Hilden, Germany) according to the manufacturer's protocol. Briefly frozen plaque samples were allowed to thaw at room temperature and centrifuged to obtain a bacterial pellet. Prior to bacterial DNA extraction an enzymatic lysing step was carried out where the bacterial pellet was resuspended in enzymatic lysing buffer mix containing Proteinase K. Samples were then processed for standard DNA extraction as per the manufacturer's protocol. Measurements of the concentration and purity of the extracted DNA were carried out using a Nanodrop 1000 spectrophotometer (Thermo Fischer Scientific, Wilmington, DE, USA).

For real time qPCR specific primers that had been previously validated for the periodontal pathogens $P$. gingivalis, A. actinomycetemcomitans, Treponema denticola and T. forsythia were used (Kozarov et al., 2006) (Supp table 2). Primers were designed using Primer- Express ${ }^{\mathrm{TM}}$ software (Applied Biosystems, Foster City, CA). Briefly, sequences for the 16S rRNA genes of the organisms of interest were aligned and inspected for regions of conserved and variable sequences. Regions specific for target bacteria were selected and evaluated using BLAST and/or Gapped BLAST searches. Only sequences with appropriate specificity were designated as probes and appropriate amplification primers were then designed. All primers were tested 
for specificity against 40- 50 laboratory strains of bacteria (Kozarov et al., 2006).

DNA isolated from a pure culture of each pathogen (P. gingivalis (ATCC 33277); A. actinomycetemcomitans (NCTC 9710); Treponema denticola (ATCC 35405); T. forsythia (ATCC 43037)) was used to generate a standard curve, with tenfold serial dilutions of genomic DNA corresponding to bacterial numbers from $10^{1}$ to $10^{6}$ cells. PCR was performed using 96 well plates on a Mx3005P qPCR System, (Agilent Technologies, Cheshire, UK). Each PCR was performed in a total volume of $10 \mu \mathrm{l}$ containing $9 \mu \mathrm{l}$ of SYBR Green master mix comprising $5 \mu \mathrm{l}$ SYBR Green and Rox (Sigma, UK), $3.9 \mu 1$ nuclease free $\mathrm{H}_{2} \mathrm{O}$ and $0.1 \mu 1$ mix of forward and reverse primers at a final concentration of $5 \mathrm{pmol} / \mu 1$ along with $1 \mu 1$ target DNA from plaque samples or dilutions of target organism standards to make a final reaction volume of $10 \mu$ l. All samples were analysed in duplicate. PCR running conditions included an initial incubation of $15 \mathrm{~min}$ at $95^{\circ} \mathrm{C}$ followed by 40 cycles consisting of denaturing at $95^{\circ} \mathrm{C}$ for 30 seconds; annealing at $55^{\circ} \mathrm{C}$ for $1 \mathrm{~min}$ followed by amplification at $72^{\circ} \mathrm{C}$ for 1 minute. For the melting curve analysis, PCR products were incubated for 1 minute at $95^{\circ} \mathrm{C}$, followed by 30 seconds at $55^{\circ} \mathrm{C}$ and the temperature was then increased to $95^{\circ} \mathrm{C}$ with a ramp rate of $0.1 / \mathrm{sec}$. PCR quantification analysis was performed using MxPro qPCR software (Agilent Technologies, Cheshire, UK) which, by default, set the minimum detection threshold. Using the standard curves for each microorganism, three additional detection thresholds were set (all of which were above the default setting): low, which included all samples with more than 10 bacteria/sample; intermediate, which included all samples with more than 100 bacteria/sample, and high which included all samples with more than 1000 bacteria/sample.

Data analysis 
Student's t-test was used to compare the age of the subjects and the number of sites with pocketing in the AgP group with the control group. Pearson's Chi Square was used to test for differences in the prevalence of each of the four bacterial species in the AgP and control groups at each detection threshold (low, intermediate or high). Odds ratios (OR) and 95\% confidence intervals $(95 \% \mathrm{CI})$ were calculated to quantify the likelihood of a specific bacterial species being associated with $\mathrm{AgP}$ at each detection threshold. The significance level for the rejection of the null hypotheses for all tests was set at $p<0.05$.

A post-hoc power calculation was performed based on $29 \%$ prevalence of $A$. actinomycetemcomitans in AgP ((Elabdeen et al., 2015) and 6\% in controls with no AgP (Elamin et al., 2011). This calculation showed that the current study had greater than $90 \%$ power to detect a difference in the prevalence of $A$. actinomycetemcomitans associated with $\mathrm{AgP}$.

\section{Results}

A total of 73 subjects with AgP (mean age 24.7, standard deviation (SD) 5.5 years) and 71 periodontally healthy controls (mean age 23.5 SD 3.7 years) were studied. There were $35 \mathrm{LAgP}$ (mean age 23.8 SD 5.3 years) and $38 \mathrm{GAgP}$ cases (mean age 25.4 SD 5.7 years). The percentage of sites with PPD $>5 \mathrm{~mm}$ was significantly higher in GAgP (51.0 SD $32.8 \%$ ) than in LAgP patients (19.3 SD 9.6\%), $p<0.0001$ (Table 1).

\section{Detection of periodontal pathogens using qPCR}

The prevalence of each bacterial species in both AgP and controls, at each detection threshold, is shown in Tables 2, 3 and 4. The frequency with which each species was identified fell as the detection threshold increased. At the lowest detection threshold ( $>10^{1}$ cells) P. gingivalis was 
identified in $68.5 \%$ of cases which was significantly higher $(p<0.0001)$ than in the controls (32.3\%). At the intermediate $\left(>10^{2}\right.$ cells) and high $\left(>10^{3}\right.$ cells) thresholds $P$. gingivalis was not significantly associated with $\mathrm{AgP}$ (Tables 3, 4).

T. forsythia was significantly associated with disease at all the thresholds applied. The prevalence of $T$. forsythia was above $85 \%$ in $\mathrm{AgP}$ at all detection thresholds. In contrast the healthy controls had a of T. forsythia prevalence of less than $30 \%$ at the highest threshold. As can be seen in Table 4, the association of T. forsythia with $\mathrm{AgP}$ was strongest $(\mathrm{OR}=15.17)$ at the highest detection threshold.

T. denticola was identified in nearly all the AgP cases and controls at the lowest level of detection and was significantly $(p<0.01)$ more frequently identified in $\mathrm{AgP}$ at the intermediate detection threshold (Tables 2, 2). At the highest detection threshold T. denticola was the most prevalent (57\%) species in the controls (Table 4).

A. actinomycetemcomitans was not associated with AgP at any detection threshold (Tables 2, 3, 4). At the low and intermediate detection thresholds A. actinomycetemcomitans was the bacterial species least frequently identified. At the highest threshold a slightly higher frequency of $A$. actinomycetemcomitans (14\%) than P. gingivalis (10\%) was found in $\mathrm{AgP}$ cases.

In general, the bacterial species studied were more frequently identified in GAgP than LAgP (Supplementary Tables 3, 4 and 5). P. gingivalis was the only bacterial species found to be significantly more prevalent in GAgP than $\mathrm{LAgP}$ at the lowest $\left(>10^{1}\right.$ cells) detection threshold. T. forsythia remained at very high frequency in $\mathrm{GAgP}$ at all thresholds and was significantly more prevalent than in LAgP at the intermediate and highest thresholds. No significant 
differences in the prevalence of A. actinomycetemcomitans between GAgP and LAgP were found at any threshold.

\section{Discussion}

This study investigated the prevalence of four putative periodontal pathogens using real time qPCR in a group of Sudanese patients with AgP compared with healthy controls. The results broadly agreed with others which have suggested the red complex bacteria are often isolated in AgP (Fine et al., 2007; Kononen \& Muller, 2014). The detection threshold employed substantially affected the prevalence of each specific bacterial species investigated. At the lowest level of detection ( $>10^{1}$ cells) P. gingivalis and T. forsythia were more prevalent in AgP than controls whereas $T$. denticola was identified in virtually all AgP cases and controls. At the highest threshold level of detection $\left(>10^{3}\right.$ cells) only $T$. forsythia remained significantly more prevalent in AgP. The prevalence of A. actinomycetemcomitans was low irrespective of the threshold of detection with no significant differences between $\mathrm{AgP}$ and controls. We found that P. gingivalis at the lowest detection level, T. denticola at the intermediate detection level and T. forsythia at the intermediate and highest detection levels were more prevalent in GAgP than LAgP. We did not however, find significant differences in the prevalence of $A$. actinomycetemcomitans in LAgP compared to the generalised form of the disease.

Microbiological findings for AgP differ between various populations worldwide (Kononen \& Muller, 2014), however, a number of studies have identified the red complex microorganisms investigated in the current study, namely $P$. gingivalis, $T$. forsythia and $T$. denticola to be associated with AgP (Lopez et al., 1996; Ximenez-Fyvie et al., 2006; Feng et al.,2014). The bacterium with the strongest association with $\mathrm{AgP}$ in the current study was $T$. forsythia. At all levels of detection T. forsythia was identified in a high proportion (>85\%) of the AgP cases and 
at a significantly higher prevalence than in controls. At the highest threshold of detection $\left(>10^{3}\right.$ cells) there was a threefold higher prevalence of T. forsythia in AgP cases compared with controls.

T. denticola was identified in the majority of both cases and controls at all levels of detection. Even in the control samples $57 \%$ were shown to have $T$. denticola above the highest threshold $\left(>10^{3}\right.$ cells). It is possible that at least some of the bacteria identified may be present because local conditions have contributed to providing a supportive habitat (Bartold \&Van Dyke, 2013). In fact, previous studies from African populations have reported very high levels of spirochaetes in subgingival plaque from subjects who were classified as resistant to periodontitis (Africa et al., 1985; Reddy et al., 1986). Studies in other ethnic groups also showed a high prevalence of $T$. denticola in healthy controls (Feng et al., 2014)

Lowering the detection threshold increased the probability of identifying the specific bacterial species studied. It was only at the lowest detection threshold ( $>10^{1}$ cells) that $P$. gingivalis was present at a significantly higher prevalence in AgP compared with controls. However, it could be argued that if bacteria are present at very low levels they are unlikely to be significant in disease pathogenesis. Recently, it has been hypothesised that periodontitis may be the result of dysbiosis (Hajishengallis et al., 2012). Evidence has been presented to show that the presence of certain keystone microbial species such as $P$. gingivalis, even at low-abundance, can orchestrate inflammatory disease by remodelling a normally benign microbiota into a dysbiotic one (Hajishengallis, 2011).

The prevalence of AgP is much higher in African than other populations worldwide (Susin et al., 2014). Genetically determined variances in the host response are important determinants 
of the risk of periodontitis (Divaris et al., 2013) and these may result in alterations in the subgingival environment leading to the emergence of periodontal pathogens (Bartold et al., 2013). There have been limited investigations in African populations, however, one recent study found that a genetic variant (rs1537415) in the glycosyl transferase gene GLT6D1 was associated with aggressive periodontitis in a Sudanese population (Hashim et al., 2015). Further work is required to fully define the genetic factors which are important in $\mathrm{AgP}$. It is possible that if the influence of genetic variability is strong, the role of the bacterial species may be less important (Lopez et al., 2015).

A. actinomycetemcomitans was the least prevalent of the 4 species investigated and there were no significant differences in its prevalence between cases and controls. The prevalence levels of $A$. actinomycetemcomitans were broadly similar to those reported in other studies (Albandar et al., 1997; Mullally et al., 2000; Takeuchi et al., 2003). Longitudinal studies have established a role for A. actinomycetemcomitans in the development of LAgP (Haubek et al., 2008; Fine et al., 2013) but it is only a proportion of those with A. actinomycetemcomitans who go on to develop this condition (Albandar et al., 1997). It may be that as AgP progresses there are changes in the local conditions which interfere with the growth of organisms such as $A$. actinomycetemcomitans while encouraging the growth of others such as T. forsythia thereby resulting in a change to a more polymicrobial anaerobic flora (Aberg et al., 2015). In the current study subgingival plaque sample were obtained from subjects in whom $70 \%$ of disease sites have $\geq 5 \mathrm{~mm}$ pocket depth. It has been shown that while $A$. actinomycetemcomitans can flourish in shallow and intermediate depth pockets (Hamlet et al., 2001; Faveri et al., 2009) the odds of a site containing this bacterium decrease in deeper pockets (Riep et al., 2009; Dahlén et al., 2014). Differences may therefore reflect variations in both the sampling strategy adopted (Winning et al., 2015) and in the clinical status of sites sampled. 
There have been two previous studies from Sudan which have investigated the prevalence of A. actinomycetemcomitans in AgP cases and controls. The first study used PCR to identify $A$. actinomycetemcomitans in $71 \% \mathrm{AgP}$ cases and 6\% controls (total of 17 patients in each category) and it was then concluded that $A$. actinomycetemcomitans might be a useful marker of increased risk of developing AgP in young Sudanese (Elamin et al., 2011). The cases studied were high school students, on average, 15 years old, and therefore almost 10 years younger than the young adults who were studied in the current work. The second study involved AgP patients seeking treatment at specialist unit in Khartoum with an age and gender distribution broadly similar (Elabdeen et al., 2015) to the current study but they may have differed in relation to disease progression and severity. Using qPCR A. actinomycetemcomitans was identified in $29 \%$ (of 19) AgP cases but not in controls (Elabdeen et al., 2015). This was similar to the prevalence in the current study where at the lowest threshold A. actinomycetemcomitans was found in $26 \%$ of $\mathrm{AgP}$, however, it was also identified in $14 \%$ of controls. Neither of the previous studies on Sudanese populations investigated the red complex bacterial species $P$. gingivalis, $T$. forsythia and T. denticola.

This study investigated a limited number of bacterial species and it did not collect data on a number of possible confounding factors such as socioeconomic status. The study was cross sectional and therefore not able to identify bacterial species associated with the causation of AgP. The results however agreed in general with others which have identified bacterial species from the red complex amongst those with a strong association with established $\mathrm{AgP}$ accepting that this may not reflect an important role in causation. Despite differences in the microbiological methodology adopted the results add to data collected in this region of Africa where there is a high prevalence of AgP. 


\section{Conclusion}

In summary, four putative periodontal pathogens $P$. gingivalis, A. actinomycetemcomitans $T$. denticola and T. forsythia were detectable in both AgP cases and healthy controls in Sudan. T. forsythia was present with a higher prevalence in $\mathrm{AgP}$ at all detection thresholds whereas it was only at the lowest level that $P$. gingivalis was significantly more prevalent in AgP than controls in the Sudanese subjects investigated. A. actinomycetemcomitans was identified less frequently than the other bacterial species investigated and there was no difference in its prevalence in the localized or generalized form of the disease.

\section{Acknowledgment}

The authors would like to thank Miss Catherine Fulton for expert technical assistance.

\section{Compliance with Ethical Standards:}

\section{Conflict of interest:}

Nada Hashim: Declares that she has no conflict of interest

Gerard Linden: Declares that he has no conflict of interest

Lewis Wining: Declares that he has no conflict of interest

Muntaser Ibrahim: Declares that he has no conflict of interest

Bakri Gasmalla: Declares that he has no conflict of interest

Fionnuala Lundy: Declares that she has no conflict of interest

Ikhlas El Karim: Declares that she has no conflict of interest 


\section{Funding:}

The work is part of a $\mathrm{PhD}$ project awarded and supported by the Graduate College Khartoum University, Sudan

\section{Ethical Approval:}

All procedures performed in this study involving human participants were in accordance with the ethical standards of the institutional and/or national research committee and with the 1964 Helsinki declaration and its later amendments or comparable ethical standards. The study protocol was approved by the Faculty of Dentistry, University of Khartoum Health Research Ethics Committee (HREC assigned number 1/2008).

\section{Informed Consent:}

Informed consent was obtained from all individual participants included in this study. 


\section{References}

Aberg, C.H., Kelk, P., \& Johansson, A. (2015). Aggregatibacter actinomycetemcomitans: Virulence of its leukotoxin and association with aggressive periodontitis. Virulence, 6, 188-195.

Africa, C.W., Parker, J.R., \& Reddy, J. (1985). Bacteriological studies of subgingival plaque in a periodontitis-resistant population. 1. Dark-field microscopic studies. Journal of Periodontal Research, 20, 1-7.

Albandar, J.M., Brown, L.J., \& Loe, H. (1997). Putative periodontal pathogens in subgingival plaque of young adults with and without early-onset periodontitis. Journal of Periodontology, $68,973-981$.

Armitage, G.C. (1999). Development of a classification system for periodontal diseases and conditions. Annals of Periodontology, 4, 1-6.

Armitage, G.C. (2004). Periodontal diagnoses and classification of periodontal diseases. Periodontology 2000, 34, 9-21.

Asikainen, S., Chen, C., Slots, J. (1996). Likelihood of transmitting Actinobacillus actinomycetemcomitans and Porphyromonas gingivalis in families with periodontitis. Oral Microbiology and Immunology, 11, 387-394.

Bartold, P.M., \& Van Dyke, T.E. (2013). Periodontitis: a host-mediated disruption of microbial homeostasis. Unlearning learned concepts. Periodontology 2000, 62, 203-217.

Dahlén, G., Claesson, R., Aberg, CH., Haubek, D., Johansson, A., Kwamin, F.(2014). Subgingival bacteria in Ghanaian adolescents with or without progression of attachment loss. Journal of Oral Microbiology, doi: 10.3402/jom.v6.23977. eCollection 2014.

Divaris, K., Monda, K.L., North, K.E, Olshan, A.F., Reynolds, L.M., Hsueh W.C. et al. (2013). Exploring the genetic basis of chronic periodontitis: a genome-wide association study. Human Molecular Genetics, 22, 2312-2324. 
Dogan, B., Kipalev, A.S., Ökte, E., Sultan, N., Asikainen, S.E. (2008). Consistent intrafamilial transmission of Actinobacillus actinomycetemcomitans despite clonal diversity. Journal of Periodontology, 79, 307-315.

Elabdeen, H.R.Z., Mustafa, M., Hasturk, H., Klepac-Cerai, V., Ali, R.W., Paster B.J. et al. (2015). Subgingival microbial profiles of Sudanese patients with aggressive periodontitis. Journal of Periodontal Research, 50, 674-682.

Elamin, A., Albandar, J.M., Poulsen, K., Ali, R.W., \& Bakken, V. (2011). Prevalence of Aggregatibacter actinomycetemcomitans in Sudanese patients with aggressive periodontitis: a case-control study. Journal of Periodontal Research, 46, 285-291.

Elamin, A., Skaug, N., Ali, R.W., Bakken, V., \& Albandar, J.M. (2010). Ethnic disparities in the prevalence of periodontitis among high school students in Sudan. Journal of Periodontology, 81, 891-896.

Faveri, M., Figueiredo, L.C., Duarte, P.M., Mestnik, M.J., Mayer, M.P.A., \& Feres, M. (2009). Microbiological profile of untreated subjects with localized aggressive periodontitis. Journal of Clinical Periodontology, 36, 739-749.

Feng, X.H., Zhang, L., Xu, L., Meng, H., Lu, R., Chen, Z. et al. (2014). Detection of eight periodontal microorganisms and distribution of Porphyromonas gingivalis fimA genotypes in Chinese patients with aggressive periodontitis. Journal of Periodontology, 85, 150-159.

Fine, D.H., Markowitz, K., Fairlie, K., Tischio-Bereski, D., Ferrendiz, J., Furgang, D. et al. (2013). A consortium of Aggregatibacter actinomycetemcomitans, Streptococcus parasanguinis, and Filifactor alocis is present in sites prior to bone loss in a longitudinal study of localized aggressive periodontitis. Journal of Clinical Microbiology, 51, 2850-2861.

Fine, D.H., Markowitz, K., Furgang, D., Fairlie, K., Ferrendiz, J., Nasri, C. et al. (2007). Aggregatibacter actinomycetemcomitans and its relationship to initiation of localized aggressive periodontitis: Longitudinal cohort study of initially healthy adolescents. Journal of Clinical Microbiology, 45(12), 3859-3869. 
Hamlet, S.M., Cullinan, M.P., Westerman, B., Lindeman, M., Bird, P.S., Palmer, J. et al (2001). Distribution of Actinobacillus actinomycetemcomitans, Porphyromonas gingivalis and Prevotella intermedia in an Australian population. Journal of Clinical Periodontology, 28, 1163-1171.

Hajishengallis, G., Darveau, R.P., \& Curtis, M.A. (2012). The keystone-pathogen hypothesis. Nature Rev Microbiology, 10, 717-725.

Hajishengallis, G., Liang, S., Payne, M.A., Hashim A., Jotwani R., Eskan M.A. et al. (2011). Low-abundance biofilm species orchestrates inflammatory periodontal disease through the commensal microbiota and complement. Cell Host Microbe, 10,497-506.

Hashim, N.T., Linden, G.J., Ibrahim, M.E., Gismalla B.G., Lundy F.T., Hughes F.J. et al. (2015). Replication of the association of GLT6D1 with aggressive periodontitis in a Sudanese population. Journal of Clinical Periodontology, 42, 319-324.

Haubek, D., Ennibi, O.K., Poulsen, K., Vaeth, M., Poulsen, S., \& Kilian, M. (2008). Risk of aggressive periodontitis in adolescent carriers of the JP2 clone of Aggregatibacter (Actinobacillus) actinomycetemcomitans in Morocco: a prospective longitudinal cohort study. Lancet, 371(9608), 237-242.

Hodge, P.J., Teague, P.W., Wright, A.F., \& Kinane, D.F. (2000). Clinical and genetic analysis of a large north European Caucasian family affected by early-onset periodontitis. Journal of Dental Research, 79, 857-863.

Höglund Åberg, C., Kwamin, F., Claesson, R., Dahlén, G., Johansson, A., Haubek, D. (2014). Progression of attachment loss is strongly associated with presence of the JP2 genotype of Aggregatibacter actinomycetemcomitans: a prospective cohort study of a young adolescent population. Journal of Clinical Periodontology, 4, 232-241.

Kamma, J.J., Nakou, M., Gmur, R., \& Baehni, P.C. (2004). Microbiological profile of early onset/aggressive periodontitis patients. Oral Microbiology and Immunology, 19, 314-321. 
Kononen, E., \& Muller, H.P. (2014). Microbiology of aggressive periodontitis. Periodontology 2000, 65, 46-78.

Kozarov, E., Sweier, D., Shelburne, C., Progulske-Fox, A., \& Lopatin, D. (2006). Detection of bacterial DNA in atheromatous plaques by quantitative PCR. Microbes and Infection, 8, 687693.

Lopez, R., Hujoel, P., \& Belibasakis, GN. (2015). On putative periodontal pathogens: an epidemiological perspective. Virulence, 6, 249-257.

Lopez, N.J., Mellado, J.C., \& Leighton, G.X. (1996). Occurrence of Actinobacillus actinomycetemcomitans, Porphyromonas gingivalis and Prevotella intermedia in juvenile periodontitis. Journal of Clinical Periodontology 23, 101-105.

Mullally, B.H., Dace, B., Shelburne, C.E., Wolff, L.F., \& Coulter, W.A. (2000). Prevalence of periodontal pathogens in localized and generalized forms of early-onset periodontitis. Journal of Periodontal Research, 35, 232-241.

Reddy, J., Africa, C.W., \& Parker, J.R. (1986). Dark-field microscopy of subgingival plaque of an urban black-population with poor oral hygiene. Journal of Clinical Periodontology, 13, 578582.

Riep, B., Edesi-Neuss, L., Claessen, F., Skarabis, H., Ehmke, B., Flemmig, T.F. et al. (2009). Are putative periodontal pathogens reliable diagnostic markers? Journal of Clinical Microbiology 47, 1705-1711.

Susin, C., Haas, A.N., \& Albandar, J.M. (2014). Epidemiology and demographics of aggressive periodontitis. Periodontology 2000, 65, 27-45.

Takeuchi, Y., Umeda, M., Ishizuka, M., Huang, Y., \& Ishikawa, I. (2003). Prevalence of periodontopathic bacteria in aggressive periodontitis patients in a Japanese population. Journal of Periodontology, 74,1460-1469.

Winning, L., Patterson, C.C., Cullen, K.M., Stevenson K.A., Lundy F.T., Kee, F. et al (2015). 
The association between subgingival periodontal pathogens and systemic inflammation. Journal of Clinical Periodontology, 42, 799-806.

Ximenez-Fyvie, L.A., Almaguer-Flores, A., Jacobo-Soto, V., Lara-Cordoba, M., MorenoBorjas, J.Y., \& Alcantara-Maruri, E. (2006). Subgingival microbiota of periodontally untreated Mexican subjects with generalized aggressive periodontitis. Journal of Clinical Periodontology, 33, 869-877. 
Table1: Clinical indices for cases with localised and generalised AgP and healthy controls. Differences in number of sites compared by t-test, ${ }^{*}=p<0.001$ ). PI: (Plaque index); PD: (Pocket depth); CAL: (Clinical attachment level).

\begin{tabular}{llll}
\hline & LAgP $(n=35)$ & GAgP $(n=38)$ & Healthy $(n=71)$ \\
\hline Age & $23.8( \pm 5.3)$ & $25.4( \pm 5.7)$ & $23.5( \pm 3.7)$ \\
PI & $1.03( \pm 0.076)$ & $1.14( \pm 0.23)$ & $0.76( \pm 0.41)$ \\
$\mathrm{PD} \geq 5 \mathrm{~mm}$ & $19.3( \pm 9.6)$ & $51.0( \pm 32.8)^{*}$ & 0.0 \\
$\mathrm{CAL} \geq 5 \mathrm{~mm}$ & $28.44( \pm 12.10)$ & $63.15( \pm 38.30) *$ & 0.0 \\
\hline
\end{tabular}

Table 2. Prevalence of periodontal pathogens $P$. gingivalis $(P g) ; T$. forsythia (Tf); $A$. actinomycetemcomitans $(\mathrm{Aa})$ and Treponema denticola $(\mathrm{Td})$ in AgP subjects and controls at low threshold values ( $>10^{1}$ cells). Odds ratios are corrected for gender. Differences in prevalence tested by Pearson's Chi Square.

\begin{tabular}{lcccc}
\hline & $\begin{array}{c}\text { AgP } \\
\mathrm{n}=73\end{array}$ & $\begin{array}{c}\text { Controls } \\
\mathrm{n}=71\end{array}$ & $p$ value & $\begin{array}{c}\text { Odds ratio } \\
(95 \% \mathrm{Cl})\end{array}$ \\
\hline$P g$ & $50(68.5 \%)$ & $23(32.3 \%)$ & 0.0001 & $4.60(2.27-9.33)$ \\
$T f$ & $71(97.3 \%)$ & $56(78.9 \%)$ & 0.0006 & $9.13(1.99-41.74)$ \\
$\mathrm{Aa}$ & $19(26.0 \%)$ & $13(18.6 \%)$ & 0.28 & $1.54(0.70-3.43)$ \\
$T d$ & $68(95.8 \%)$ & $68(97.1 \%)$ & 0.66 & $0.76(0.12-4.73)$ \\
\hline
\end{tabular}


Table 3. Prevalence of periodontal pathogens $P$. gingivalis $(P g) ; T$. forsythia $(T f) ; A$. actinomycetemcomitans $(\mathrm{Aa})$ and Treponema denticola $(\mathrm{Td})$ in $\mathrm{AgP}$ subjects and controls at intermediate threshold values $\left(>10^{2}\right.$ cells). Odds ratios are corrected for gender. Differences in prevalence tested by Pearson's Chi Square.

\begin{tabular}{lllll}
\hline & $\begin{array}{l}\text { AgP } \\
\mathrm{n}=73\end{array}$ & $\begin{array}{l}\text { Controls } \\
\mathrm{n}=71\end{array}$ & $p$ value & $\begin{array}{l}\text { Odds ratio } \\
(95 \% \mathrm{Cl})\end{array}$ \\
\hline$P g$ & $28(38.4 \%)$ & $18(25.3 \%)$ & 0.09 & $1.88(0.92-3.86)$ \\
$T f$ & $68(93.2 \%)$ & $44(62.0 \%)$ & 0.0001 & $8.10(2.89-22.69)$ \\
$\mathrm{Aa}$ & $15(20.5 \%)$ & $11(15.7 \%)$ & 0.45 & $1.38(0.59-3.27)$ \\
$T d$ & $67(94.4 \%)$ & $56(80.0 \%)$ & 0.01 & $4.04(1.25-13.03)$ \\
\hline
\end{tabular}

Table 4. Prevalence of periodontal pathogens P. gingivalis (Pg); T. forsythia (Tf); $A$. actinomycetemcomitans $(\mathrm{Aa})$ and Treponema denticola $(\mathrm{Td})$ in AgP subjects and controls at high threshold values $\left(>10^{3}\right.$ cells). Odds ratios are corrected for gender. Differences in prevalence tested by Pearson's Chi Square.

\begin{tabular}{lcccl}
\hline & $\begin{array}{c}\text { AgP } \\
\mathrm{n}=73\end{array}$ & $\begin{array}{c}\text { Controls } \\
\mathrm{n}=71\end{array}$ & $p$ value & $\begin{array}{c}\text { Odds ratio } \\
(95 \% \mathrm{Cl})\end{array}$ \\
\hline $\mathrm{Pg}$ & $7(9.6 \%)$ & $14(19.7 \%)$ & 0.085 & $0.41(0.16-1.11)$ \\
$T f$ & $63(86.3 \%)$ & $21(29.6 \%)$ & 0.0001 & $15.17(6.51-35.35)$ \\
$\mathrm{Aa}$ & $10(13.7 \%)$ & $6(8.6 \%)$ & 0.33 & $1.59(0.54-4.67)$ \\
$T d$ & $51(71.8 \%)$ & $40(57.1 \%)$ & 0.07 & $1.93(0.95-3.91)$ \\
\hline
\end{tabular}


